\title{
Experimental study on convection heat transfer and air drag in sinter layer
}

\author{
PAN Li-sheng(潘利生) ${ }^{1}$, WEI Xiao-lin(魏小林) ${ }^{1}$, PENG Yan(彭岩 $)^{2}$, \\ SHI Xiao-bao(时小宝) ${ }^{2}$, LIU Huai-liang(刘怀亮) ${ }^{2}$ \\ 1. State Key Laboratory of High Temperature Gas Dynamics, Institute of Mechanics, \\ Chinese Academy of Sciences, Beijing 100190, China; \\ 2. Citic Heavy Industries Co., Ltd., Luoyang 471039, China \\ (C) Central South University Press and Springer-Verlag Berlin Heidelberg 2015
}

\begin{abstract}
Convection heat transfer coefficient and air pressure drop in sinter layer are important factors for the design of sinter cooling craft. Due to the lack of necessary data, the two parameters are studied by experimental method. The experimental results show that heat conduction of sinter impacts the measurement of convection heat transfer coefficient. Convection heat transfer increases with the increase of air volumetric flow rate. Sinter layer without small particles (sample I) gives higher convection heat transfer coefficient than that with small particles (sample II). Under the considered conditions, volumetric convection heat transfer coefficient is in the range of $400-1800 \mathrm{~W} /\left(\mathrm{m}^{3} \cdot{ }^{\circ} \mathrm{C}\right)$. Air pressure drop in sinter layer increases with the increase of normal superficial velocity, as well as with the rise of air temperature. Additionally, air pressure drop also depends on sinter particle size distribution. In considered experimental conditions, pressure drop in sinter sample II is 2-3 times that in sinter sample I, which resulted from $17 \%$ small scale particles in sinter sample II.
\end{abstract}

Key words: sinter layer; convection heat transfer; pressure drop

\section{Introduction}

Smelting and pressing of ferrous metals consume $16.9 \%$ of total energy consumption in 2011 in China [1]. Confronted with the serious energy shortage, energy conservation in metallurgical industry is becoming more and more important. In this high energy consumption industry, energy consumption proportion of sinter production process is $10 \%-15 \%$ and $20 \%-30 \%$ of the total energy consumption is discharged into the atmosphere as sensible heat of exhaust cooling air [2].

Sinter cooling is an important process in sinter production process and determines sinter quality. Waste heat from sinter in the cooling process is usually used to generate steam or electricity power. Researchers have executed much important study on the utilization of sinter waste heat. CAPUTO et al [3-6] executed much important research on heat recovery from cooling sinter. A simulation model for heat recovery in gas-solid moving bed is proposed to evaluate thermal characteristics of sinter cooler in different operating conditions [3] and a two-dimensional time-dependent convection-conduction heat transfer model for cooling bed is developed to optimize the size of air capture hoods for heat recovery system [4]. CAPUTO et al [5-6] also carried out research on optimization of heat recovery scheme based on plant complexities, capital investment, operating expenses and benefits of the schemes.

With the development of computer, computational fluid dynamics (CFD) is becoming a more and more important method to solve the flow and heat transfer problems. Much research was carried out to reveal the impact of the main parameters on the performance of waste heat recovery process [7-11]. JANG and CHIU [12] obtained a correlation equation among particle diameter, Reynolds number and Nuseelt number.

In conventional craft, ring cold machine is used to cool the sinter and the upper collecting hood is used to collect the hot air which can generate steam in waste heat boiler. However, it is hard to seal well between the ring cold machine and the upper collecting hood. Leakage rate of sintering and cooling system is up to $30 \%-60 \%$ and the leakage has become a bottleneck of recovering waste heat efficiently [13]. Therefore, conventional craft gives very low efficiency in recovering heat energy because of air leakage in the system. In order to solve the problem, new sinter cooling craft is designed [14-15]. There isn't motive seal in this new cooling device which can give much higher heat recovery efficiency. Two parameters, namely convection heat transfer coefficient and air pressure drop in sinter layer, are important for

Foundation item: Project(51306198) supported by the National Natural Science Foundation of China

Received date: 2014-06-06; Accepted date: 2014-09-15

Corresponding author: PAN Li-sheng, Assistant Research Fellow; Tel: +86-10-82544234; E-mail: panlisheng@imech.ac.cn 
new craft design. In this article, experimental studies on convection heat transfer coefficient and air pressure drop in sinter layer are executed.

\section{Methodology}

\subsection{Experimental system}

An experimental system was established as shown in Fig. 1. The system contains an air blower, an air flow meter, an air electrical heater, a sinter furnace and a vitreous U-tube manometer. Diameter of the sinter furnace is $0.3 \mathrm{~m}$ and thickness of the sinter layer is $1 \mathrm{~m}$. Six temperature measure points have been fixed in the sinter layer evenly along vertical direction. Therefore, the layer is divided into five units. Not only each sinter layer unit but also the whole sinter layer can be investigated by experiment method. In order to reduce heat loss from sinter furnace to ambient, the outside wall of the sinter furnace is insulated by wrapping thick rockwool.

There are two sheathed thermocouples at each temperature measure point. One thermocouple is used to measure air temperature in sinter layer and the other is used to measure temperature on sinter outside surface. A perforated casing is used outside the thermocouple which is used to measure air temperature to separate the thermocouple from the sinter. A spring is used on the thermocouple which is used to measure temperature on sinter outside surface to ensure that the thermocouple is compressed tightly on sinter surface. Air pressure drop in sinter layer is measured by the vitreous U-tube manometer both sides of which are connected with the sinter furnace inlet and the outlet, respectively. Pressure difference is shown by water height difference in the U-tube.
During the experimental process, a frequency converter fixed on air blower is used to control air volumetric flow rate in the system. Air flow meter is used to give the value of air volumetric flow rate. The electric heater can enhance temperature of the air that flows along the equipment if the device switch is turned on. In heat transfer experiment, hot air heats the cold sinter layer firstly and then cold air cools the sinter layer. In air pressure drop experiment or sinter cooling experiment, the switch of electric heater is turned off. The exhaust gas is discharged by exhaust pipe.

\subsection{Sinter sample}

Two typical samples are used in this experimental study. One sinter sample is screened sinter and the other one is original sinter that is obtained from steel enterprise. Screened sinter doesn't contain small sinter particles whose sizes are less than $10 \mathrm{~mm}$ while the original sinter contains small sinter particles. These two sinter samples are used to establish sinter layer in sinter furnace, respectively. The detailed compositions of the two sinter samples are listed in Table 1.

Table 1 Compositions of two experimental sinter samples

\begin{tabular}{ccccccc}
\hline & \multicolumn{6}{c}{ Composition/\% } \\
\cline { 2 - 7 } Sample & \multirow{2}{*}{$\begin{array}{c}5- \\
0-5 \mathrm{~mm}\end{array}$} & $\begin{array}{c}5- \\
10 \mathrm{~mm}\end{array}$ & $18 \mathrm{~mm}$ & $30 \mathrm{~mm}$ & $40 \mathrm{~mm}$ & $>50 \mathrm{~mm}$ \\
\hline I & 0 & 0 & 12.40 & 55.44 & 22.95 & 9.21 \\
II & 8.52 & 8.10 & 10.34 & 46.23 & 19.13 & 7.68 \\
\hline
\end{tabular}

\subsection{Analysis method}

Convection heat transfer experiment contains two processes, namely, heating sinter process and cooling sinter process. Each process is executed using sinter sample I and sinter sample II, respectively. The air

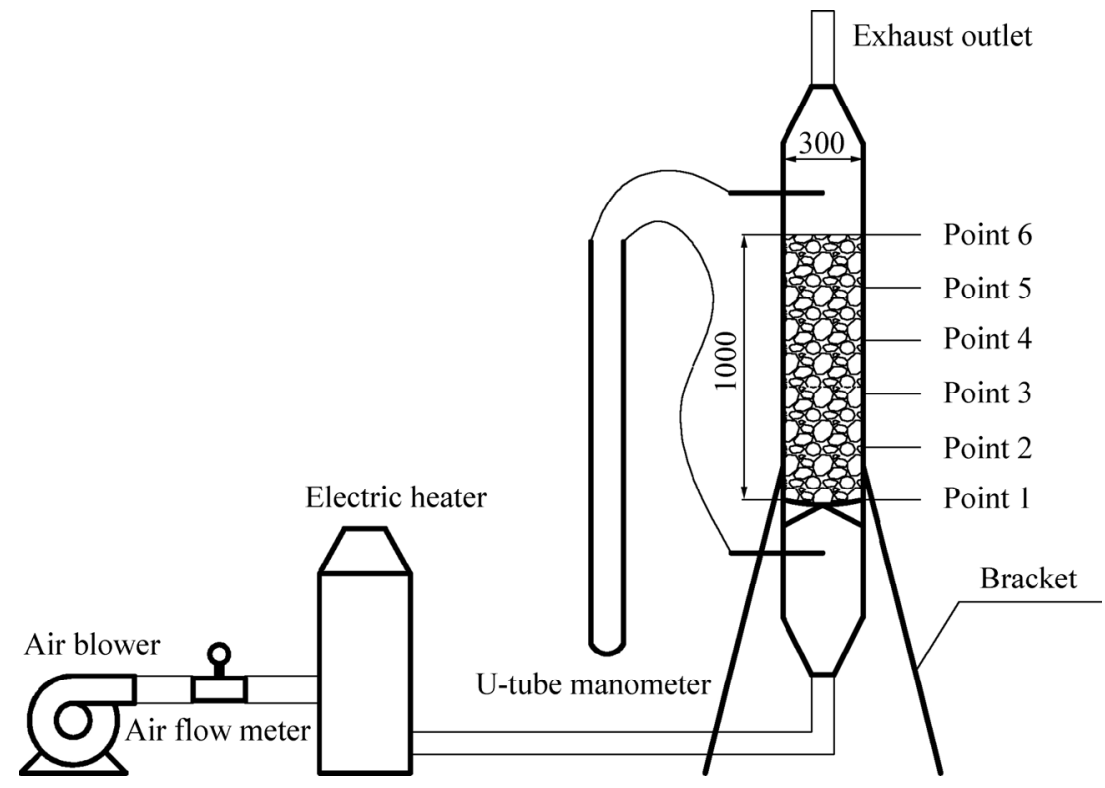

Fig. 1 Experimental system for convection heat transfer and air pressure drop in sinter layer (Unit: $\mathrm{mm}$ ) 
temperature in sinter layer inlet increases with time in heating sinter process and decreases in cooling sinter process. The reason is that temperature of electric heater increases slowly after turning on the switch while also decreases slowly after turning off the switch. Additionally, temperature difference between air and sinter varies with time. Therefore, unsteady convection heat transfer exists in both heating sinter process and cooling sinter process. When sinter is heated by the hot air, the heat transfer capacity can be calculated by

$$
Q_{\text {air,give }}=\dot{V}_{\text {air,N }} \rho_{\text {air,N }}\left(t_{\text {air,in }} c_{p, \text { air,in }}-t_{\text {air,out }} c_{p, \text { air,out }}\right) / 3600
$$

When sinter is cooled by the cold air, the heat transfer capacity can be calculated by

$$
Q_{\text {air,get }}=\dot{V}_{\text {air, } \mathrm{N}} \rho_{\text {air,N }}\left(t_{\text {air,out }} c_{p, \text { air,out }}-t_{\text {air,in }} c_{p, \text { air,in }}\right) / 3600
$$

Because of the variation of the air temperature and sinter temperature, heat capacity, temperature, and nearly specific heat are all transient. Though the sinter furnace is well insulated by wrapping thick rockwool, heat loss from the sinter to the environment is unavoidable. Efficiency of the sinter furnace can be expressed as

$$
\eta_{\text {furnace }}=\frac{\int_{\text {cooling }} Q_{\text {air,get }} \mathrm{d} \tau}{\int_{\text {heating }} Q_{\text {air,give }} \mathrm{d} \tau}
$$

It should be noted that efficiency of the sinter furnace is an average value in the whole experimental process rather than a transient value. Convection heat transfers in the five sinter layer units are all investigated. There are two process, namely, heating sinter process and cooling sinter process, for each sinter layer unit in experiment. The sinter layer keeps stationary throughout the experiment process while the air flows upwards through the sinter layer from the bottom to the top. When hot air heats the sinter layer, temperature distributions of air and sinter are similar to those shown in Fig. 2(a). When cold air cools the sinter layer, the temperature distributions of air and sinter are shown in Fig. 2(b). Logarithmic mean temperature difference (LMTD) in heating sinter process can be expressed as Eq. (4) where $\bar{t}$ is average value in specified time unit $\Delta \tau$. Convection heat transfer capacity can be calculated by Eq. (5) and Eq. (6). The volumetric heat transfer coefficient can be expressed as Eq. (7).

$$
\begin{aligned}
\Delta t_{\text {LMTD, heat }}= & {\left[\left(\bar{t}_{\text {air,down, unit }}-\bar{t}_{\text {sinter,down, unit }}\right)-\left(\bar{t}_{\text {air,up,unit }}-\right.\right.} \\
& \left.\left.\bar{t}_{\text {sinter,up,unit }}\right)\right] / \ln \left[\left(\bar{t}_{\text {air,down,unit }}-\right.\right. \\
& \left.\left.\bar{t}_{\text {sinter,down,unit }}\right) /\left(\bar{t}_{\text {air,up,unit }}-\bar{t}_{\text {sinter,up,unit }}\right)\right] \\
Q_{\text {air,give,unit }}= & \dot{V}_{\text {air,N }} \rho_{\text {air,N }}\left(\bar{t}_{\text {air,in,unit }} c_{p, \text { air,in,unit }}-\right. \\
& \left.\bar{t}_{\text {air,out,unit }} c_{p \text {,air,out,unit }}\right)
\end{aligned}
$$

$Q_{\text {convection, unit }}=Q_{\text {air,give, unit }}$

$h_{\mathrm{V}, \text { heat }}=\frac{Q_{\text {convection, unit }}}{V_{\text {unit }} \Delta t_{\mathrm{L}}}$

$Q_{\text {air,get,unit }}=\dot{V}_{\text {air,N }} \rho_{\text {air,N }}\left(\bar{t}_{\text {air,out, unit }} c_{p, \text { air,out, unit }}-\right.$ $\left.\bar{t}_{\text {air,in,unit }} c_{p \text {,air,in,unit }}\right)$

$Q_{\text {convection, unit }}=Q_{\text {air, get, unit }}$

$\begin{aligned} \Delta t_{\text {LMTD,cool }}= & {\left[\left(\bar{t}_{\text {sinter,down,unit }}-\bar{t}_{\text {air,down,unit }}\right)-\left(\bar{t}_{\text {sinter,up,unit }}-\right.\right.} \\ & \left.\left.\bar{t}_{\text {air,up,unit }}\right)\right] / \ln \left[\left(\bar{t}_{\text {sinter,down,unit }}-\right.\right. \\ & \left.\left.\bar{t}_{\text {air,down,unit }}\right) /\left(\bar{t}_{\text {sinter,up,unit }}-\bar{t}_{\text {air,up, unit }}\right)\right] \quad(10)\end{aligned}$

$h_{\mathrm{V}, \text { cool }}=\frac{Q_{\text {convection,unit }}}{V_{\text {unit }} \Delta t_{\text {LMTD,cool }}}$

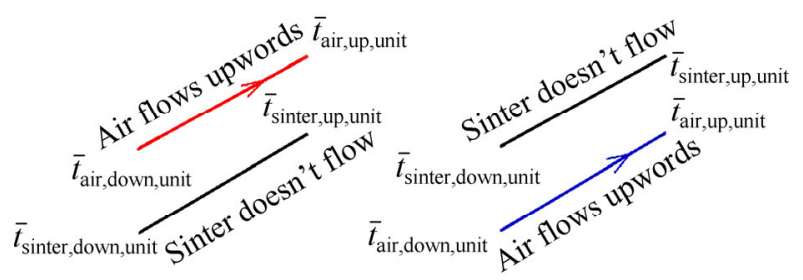

(a)

(b)

Fig. 2 Temperate distributions of air and sinter in each considered unit: (a) Air heats sinter; (b) Air cools sinter

In cooling sinter process, convection heat transfer capacity, LMTD and volumetric heat transfer coefficient can be calculated by Eqs. (8)-(11).

\section{Results and discussion}

\subsection{Convection heat transfer}

Experiment is executed to study convection heat transfer in sinter layer. Both sinter samples are selected to establish the sinter layer, respectively. For each sinter sample, several experiment series with different air volumetric flow rates are considered. The values of air volumetric flow rate are 75, 100, 125 and $150 \mathrm{~m}^{3} / \mathrm{h}$, respectively. Sinter layer is heated by hot air firstly and then is cooled by cold air. Air temperature and sinter temperature at each temperature measure point are measured by thermocouples and are used in analyzing convection heat transfer.

Figure 3 shows the temperature profiles of air and sinter at each temperature measure points in experiment series with air volumetric flow rate of $125 \mathrm{~m}^{3} / \mathrm{h}$. When the system is started up, air is gradually heated by electric heater. Then, heat energy transfers from hot air to cold sinter. Air temperature and sinter temperature increase with time. Temperature measure point 1 is located at the bottom of the sinter layer, so temperature at this point increases earlier than the other points. At the 
same time in heating sinter process, the higher the temperature measure point locates, the lower the temperature is. The electric heater can provide the maximum temperature of air is about $400{ }^{\circ} \mathrm{C}$ according to the equipment power and the air volumetric flow rate. Therefore, air temperature at temperature measure point 1 reaches about $400{ }^{\circ} \mathrm{C}$ and then keeps nearly constant. When temperatures at the other temperature measure points also reach nearly constant values, the electric heater should be turned off. In cooling sinter process, temperatures at each temperature measure points decrease with the time. The lower the temperature measure point locates, the earlier the decrease begins. In this experiment process, heat energy transfers from hot sinter to cold air. However, it should be noted that sinter temperature is higher than air temperature at temperature measure points $2-6$ in the incipient stage of heating sinter process and sinter temperature is lower than air temperature at temperature measure points $2-6$ in the incipient stage of cooling sinter process. The reason is that sinter conductivity coefficient is much high and heat energy transfers from hot sinter to cold sinter in the incipient stage of heating sinter process and cooling sinter process. In experiment series with other air volumetric flow rate, the temperature profiles are similar with this condition.

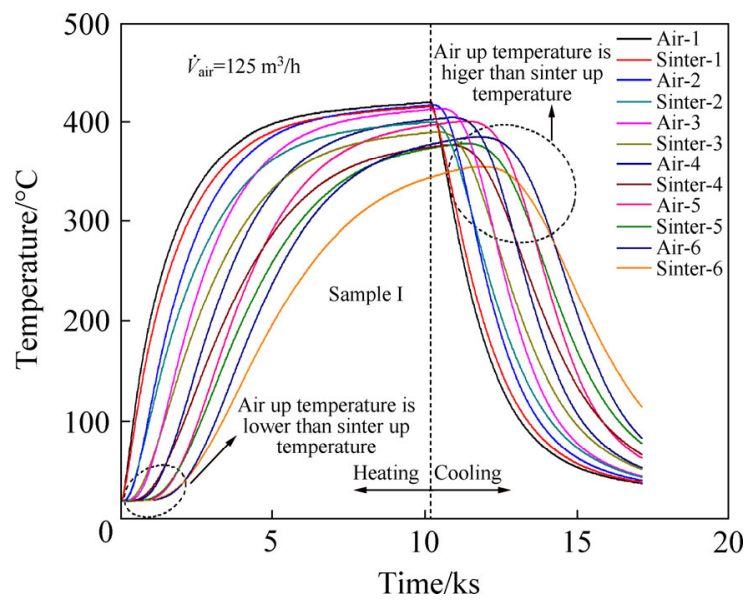

Fig. 3 Temperature profiles of air and sinter at each temperature measure points

Figure 4 shows the capacity of convection heat transfer from air to sinter in each sinter layer unit. In the figure, positive value represents that air loses heat energy and negative value indicates that air gets heat energy in sinter layer unit. With the increase of air temperature, capacity of convection heat transfer from air to sinter increases firstly and then decreases. For each sinter layer unit, there is a maximum capacity of convection heat transfer in heating sinter process and also in cooling sinter process. Capacity of convection heat transfer is determined by LMTD and convection heat transfer coefficient. The maximum value appears later and becomes smaller in higher sinter layer unit. According to the heat capacity in whole sinter layer throughout entire experiment series, thermal efficiency of the sinter furnace can be calculated by Eq. (3) and the value is $71.3 \%$.

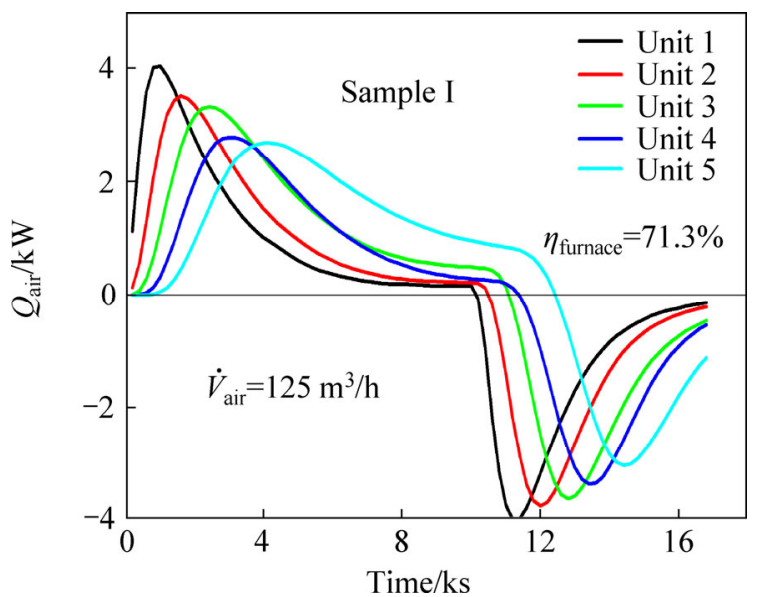

Fig. 4 Capacity of convection heat transfer from air to sinter in each sinter layer unit

According to capacity of convection heat transfer and LMTD, volumetric convection heat transfer coefficient in each sinter layer unit can be calculated by Eq. (7) and Eq. (11). Vertical heat conduction of sinter is much high in each sinter layer unit. Therefore, in the incipient stage of heating sinter process, air up temperature is lower than sinter up temperature in each sinter layer unit and is higher than sinter up temperature in the incipient stage of cooling sinter process. This phenomenon in incipient stage of heating and cooling sinter process can be recognized in Fig. 3. Accurate values of volumetric convection heat transfer coefficient can not be obtained by experimental data in the incipient stage of heating or cooling sinter. In order to get useful accurate heat transfer coefficient, steady heat transfer data in the later stage of heating and cooling sinter process are used.

Figure 5 shows volumetric convection heat transfer coefficient under different conditions. Heat transfer coefficient increases with increasing volumetric flow rate of air. Generally, heat transfer coefficient of sample I is a little higher than that of sample II. There isn't much difference between heat transfer coefficient in heating sinter process and in cooling sinter process. It is well known that convection heat transfer coefficient depends on several parameters. For example, for single-phase forced convection in a tube, heat transfer coefficient is determined by fluid parameters, such as velocity, density, dynamic viscosity, heat conduction coefficient and specific heat, and tube parameter like diameter. This correlation can be shown in the equation $h=f\left(u^{0.8}\right.$, 

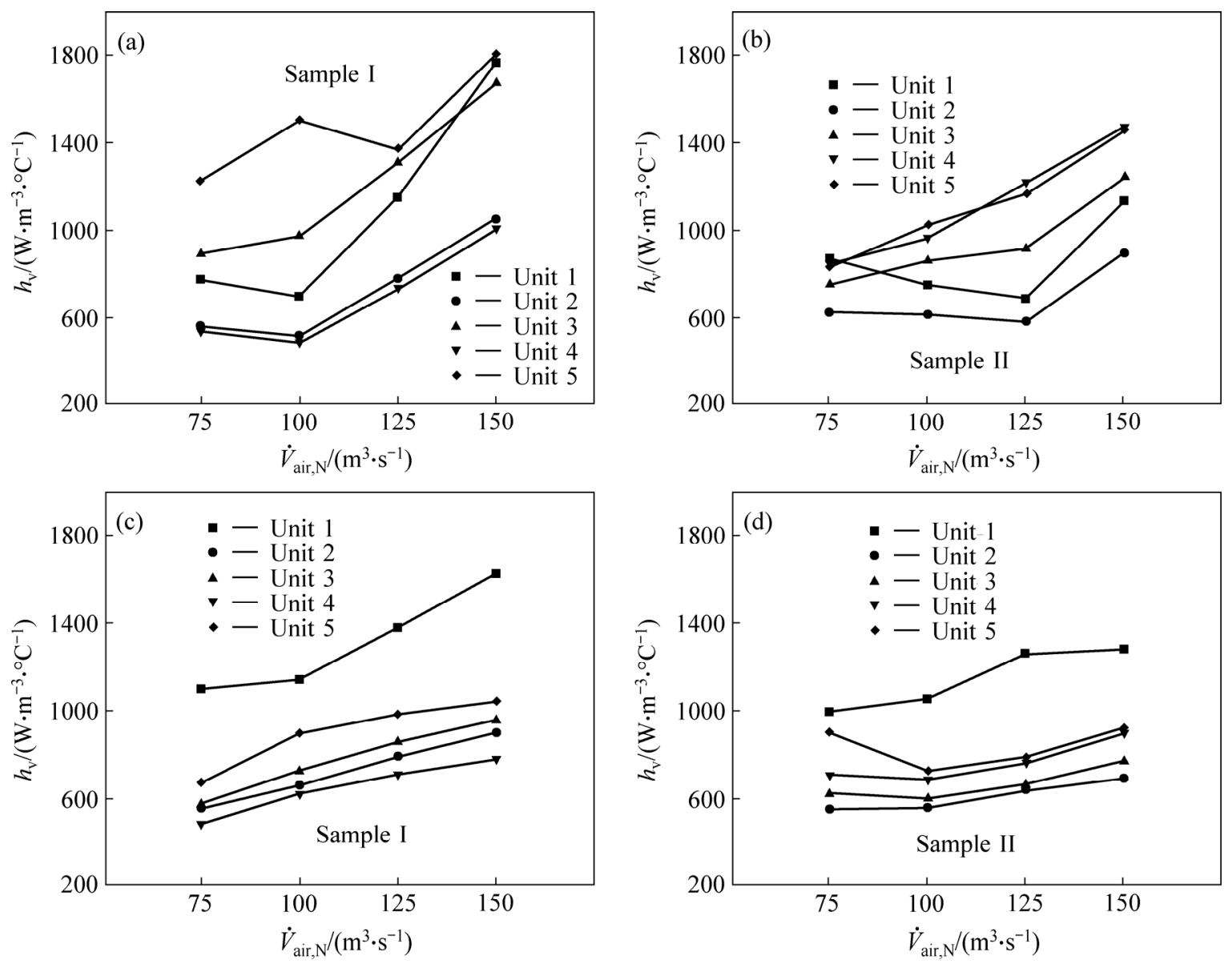

Fig. 5 Volumetric convection heat transfer coefficient in each sinter layer unit: (a, b) Heating sinter process; (c, d) Cooling sinter process

$\left.\rho^{0.8}, \lambda^{0.4}, \mu^{-0.4}, c_{p}{ }^{-0.2}, d^{-0.2}\right)$. Air velocity in sinter layer increases with the rise of normal volumetric flow rate. For this reason, heat transfer coefficient increases with the increase of normal volumetric flow rate. Sinter layer can be considered porous medium. But air flow through the sinter layer is much nonuniform. That is to say, air velocity in some situations is low while may be much high in another situation. Small sinter particle is harmful for air's flow through the sinter layer. Then, nonuniformity is more serious in sample II sinter layer. This reason can result in a fact that heat transfer reduced in situations with low velocity. Therefore, heat transfer coefficient of sample $\mathrm{I}$ is a little higher than that of sample II.

In steady heating sinter process, air temperature is about $400{ }^{\circ} \mathrm{C}$ and it is $50{ }^{\circ} \mathrm{C}$ in steady cooling sinter process. Air parameters at these two temperatures are shown in Table 2. Specific heats are nearly the same while other parameters are very different at both temperatures. At $400{ }^{\circ} \mathrm{C}$, density is lower while velocity is higher than that at $50{ }^{\circ} \mathrm{C}$. At $400{ }^{\circ} \mathrm{C}$, heat conduction coefficient and dynamic viscosity are all higher than those at $50{ }^{\circ} \mathrm{C}$. But heat conduction coefficient is helpful while dynamic viscosity is harmful for convection heat transfer. Consequently, some effects of air parameters on heat transfer coefficient counteract the others and no obvious difference can be found between heat transfer coefficient in heating sinter process and in cooling sinter process. In considered conditions, volumetric convection heat transfer coefficient is in the range of 400-1800 $\mathrm{W} /\left(\mathrm{m}^{3} \cdot{ }^{\circ} \mathrm{C}\right)$.

Table 2 Comparison of air parameters at two typical temperatures

\begin{tabular}{ccccc}
\hline $\begin{array}{c}\text { Temperature/ } \\
{ }^{\circ} \mathrm{C}\end{array}$ & $\begin{array}{c}\rho / \\
\left(\mathrm{kg} \cdot \mathrm{m}^{-3}\right)\end{array}$ & $\begin{array}{c}\lambda / \\
\left(\mathrm{W} \cdot \mathrm{m}^{-1} \cdot{ }^{\circ} \mathrm{C}^{-1}\right)\end{array}$ & $\begin{array}{c}\mu / \\
\left(10^{-5} \mathrm{~Pa} \cdot \mathrm{s}\right)\end{array}$ & $\begin{array}{c}c_{\mathrm{p}} / \\
\left(\mathrm{kJ} \cdot \mathrm{kg}^{-1} \cdot{ }^{\circ} \mathrm{C}^{-1}\right)\end{array}$ \\
\hline 400 & 0.521 & 0.0498 & 3.29 & 1.070 \\
50 & 1.085 & 0.0277 & 1.96 & 1.007 \\
\hline
\end{tabular}

\subsection{Pressure drop in sinter layer}

In this section, pressure drop of air with different temperatures in sinter layer has been tested. Three temperatures are considered, such as ambient temperature (about $20^{\circ} \mathrm{C}$ ), about $150^{\circ} \mathrm{C}$ and about $250^{\circ} \mathrm{C}$. Volumetric flow rate of air is in the range of $50-300 \mathrm{~m}^{3} / \mathrm{h}$. Also sinter sample I and sinter sample II are selected to establish the sinter layer, respectively. In the experiment, air temperature should be roughly uniform throughout 
the sinter layer.

ERGUN [16] proposed an empirical relation for describing the pressure drop through porous media based on the porosity

$$
\frac{\Delta p_{\text {drop }}}{L}=K_{1} \frac{(1-\varepsilon)^{2} \mu}{\varepsilon^{3} d^{2}} u_{\text {superficial }}+K_{2} \frac{(1-\varepsilon)}{\varepsilon^{3} d} \rho u_{\text {superficial }}^{2}
$$

where $K_{1}=150$ and $K_{2}=1.75$. As indicated in the Ergun equation, pressure drop in porous media is determined by porosity of porous media, dynamic viscosity, superficial velocity and media diameter. The equation is widely used in evaluating pressure drop in uniform size particles layer. However, for sinter samples, diameter of finished product is usually in the range of 5-40 $\mathrm{mm}$. Meanwhile, there are also some particles less than $5 \mathrm{~mm}$ or larger than $40 \mathrm{~mm}$. Consequently, among the above dominant parameters, diameter value is hard to specify for sinter layer though the size distribution can be obtained by screening. But Eq. (12) can be used in qualitative analysis of the experimental data.

As shown in Fig. 6, for each air temperature, air pressure drop increases with the increase of air superficial velocity. The higher the air temperature is, the higher the air pressure drop is. Air pressure drop in sinter layer with sinter sample II is much higher than that with sinter sample I. Obviously, air pressure drop increases with the rise of air superficial velocity when air temperature is constant, as shown in Eq. (12). The higher the air temperature is, the lower the air density is. When air normal superficial velocity is constant, air velocity increases with the increase of air temperature. Additionally, air dynamic viscosity increases with increasing air temperature. Therefore, air pressure drop increases with the rise of air temperature. Particle size determines sinter diameter and sinter porosity. The less the particle size is, the less the diameter and porosity are. Average gain diameter of sinter sample I is generally higher than that of sinter sample II, so air pressure drop with sinter sample I is much lower than that with sinter sample II.

In Ref. [17], a method was provided to estimate air pressure drop in sinter layer. The air pressure drop can be expressed as

$$
\frac{\Delta p_{\mathrm{drop}}}{L}=510 \cdot\left(u_{\text {air,superficial, } \mathrm{N}} / M\right)^{1.82}
$$

where $u_{\text {air,superficial,N }}$ represents air normal superficial velocity in sinter layer and $M$ represents permeability of sinter layer. In the equation, sinter diameter is not an input parameter, so it is more suitable than Eq. (12) for analyzing pressure drop in sinter layer. The term of $M$ can indicate sinter properties. The value of $M$ can be fined out in Fig. 7 according to screening efficiency which is measured by sieve with pore size of $12.7 \mathrm{~mm}$.
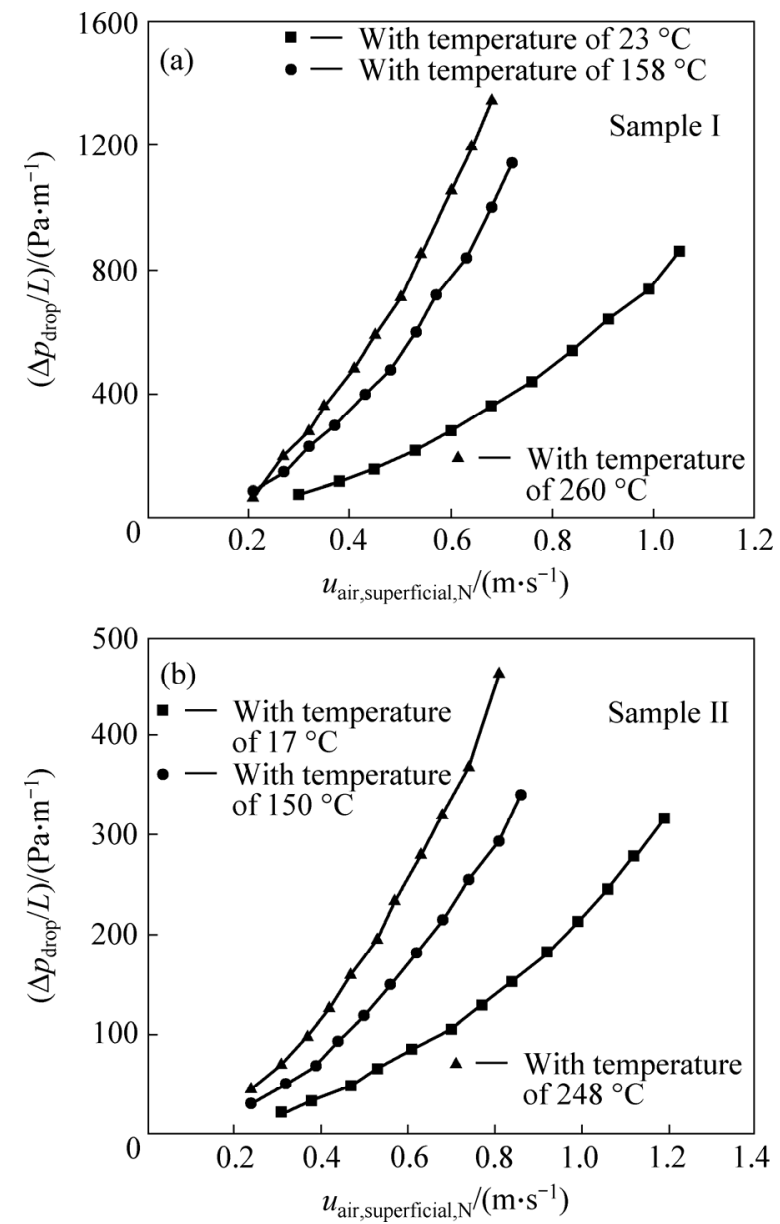

Fig. 6 Variation of air pressure drop in sinter layer with air normal superficial velocity: (a) Sample I; (b) Sample II

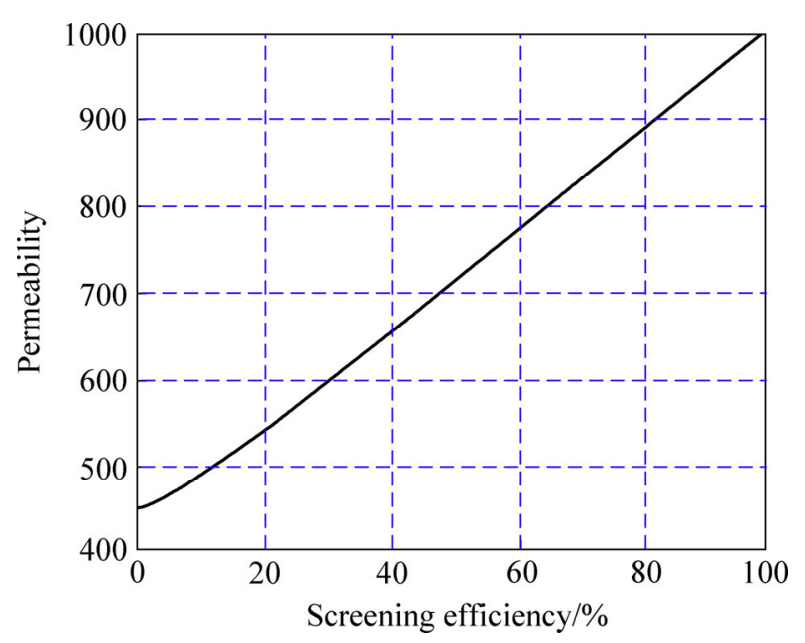

Fig. 7 Variation of permeability with screening efficiency

Experiment results and computational results obtained by estimation method are compared in Fig. 8 . As shown in Fig. 8(a), for sinter sample I, when $M$ is specified as 850 (with screening efficiency of about $75 \%$ ), experiment results are in good agreement with estimation results. Sinter sample I doesn't contain sinter particles with particle size less than $10 \mathrm{~mm}$ while contains sinter particles with particle size of 10-12.7 mm. 
Therefore, it is unreasonable to specify screening efficiency as $100 \%$. As shown in Fig. 8(b), for sinter sample II, when $M$ is specified as 500 (with screening efficiency of about $13 \%$ ), experiment results are in good agreement with estimation results. Based on the above analysis, experimental results are credible. In experimental conditions, pressure drop in sinter sample II is $2-3$ times that in sinter sample I, which resulted from $17 \%$ small scale particles in sinter sample II. Therefore, particle size is a very important factor in sinter cooling process design.
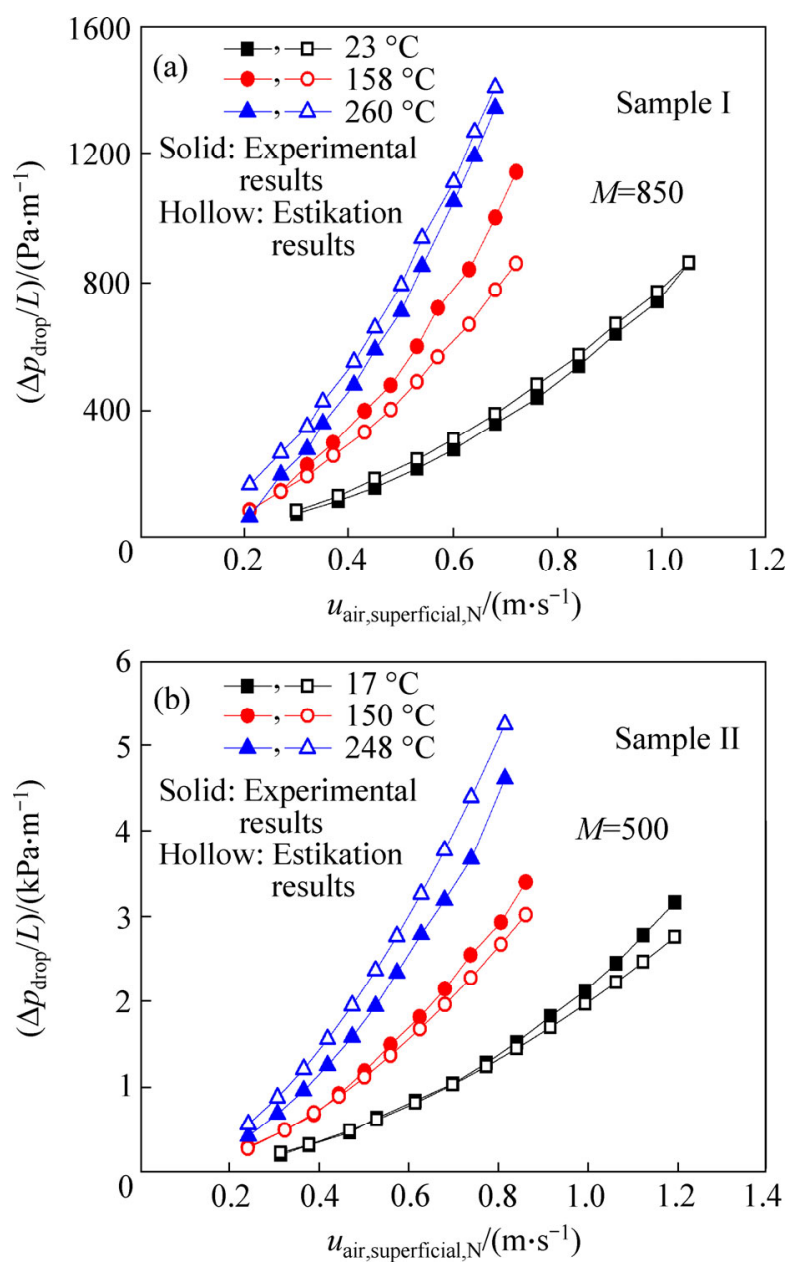

Fig. 8 Comparison between experimental results and estimation results of air pressure drop in sinter layer: (a) Sample I; (b) Sample II

\section{Conclusions}

1) Convection heat transfer coefficient and air pressure drop in sinter layer are two most important factors for the design of sinter cooling craft. An experimental system is established and studied on convection heat transfer and air pressure drop in sinter layer.

2) Heat conduction of sinter impacts the measurement of convection heat transfer coefficient. Steady heat transfer data in heating and cooling sinter process should be used to get useful accurate heat transfer coefficient. Convection heat transfer increases with the increase of air volumetric flow rate. Sinter layer without small particles gives higher heat transfer coefficient than that with small particles. Under considered conditions, volumetric convection heat transfer coefficient is in the range of $400-1800$ $\mathrm{W} /\left(\mathrm{m}^{3} \cdot{ }^{\circ} \mathrm{C}\right)$.

3) Air pressure drop in sinter layer increases with increasing normal superficial velocity, as well as with the rise of air temperature. Additionally, pressure drop of sinter sample II is much higher than that of sinter sample I. In experimental conditions, small scale particles in sinter sample II lead to that pressure drop in sinter sample II as much as 2-3 times that in sinter sample I.

\section{Nomenclature}

$c_{p} \quad$ Specific heat capacity at constant pressure $\left(\mathrm{J} /\left(\mathrm{kg} \cdot{ }^{\circ} \mathrm{C}\right)\right)$

$\lambda \quad$ Heat conduction coefficient $\left(\mathrm{W} /\left(\mathrm{m} \cdot{ }^{\circ} \mathrm{C}\right)\right)$

$\mu \quad$ Dynamic viscosity $(\mathrm{Pa} \cdot \mathrm{s})$

$\rho \quad$ Density $\left(\mathrm{kg} / \mathrm{m}^{3}\right)$

$t \quad$ Temperature $\left({ }^{\circ} \mathrm{C}\right)$

$p \quad$ Pressure (MPa)

$\tau \quad$ Time (s)

$u \quad$ Velocity $(\mathrm{m} / \mathrm{s})$

$\dot{V} \quad$ Volumetric flow rate $\left(\mathrm{m}^{3} / \mathrm{h}\right)$

$V \quad$ Volume $\left(\mathrm{m}^{3}\right)$

$Q \quad$ Heat transfer capacity (W)

$h_{\mathrm{V}} \quad$ Valid volumetric heat transfer coefficient $\left(\mathrm{W} /\left(\mathrm{m}^{3} \cdot{ }^{\circ} \mathrm{C}\right)\right)$

$g \quad$ Air drag coefficient

$d \quad$ Diameter $(\mathrm{mm})$

$\varepsilon \quad$ Porosity

$L \quad$ Height of sinter layer (m)

$M \quad$ Permeability of sinter sample

\section{Greek letters}

$\eta \quad$ Efficiency

$f \quad$ Friction coefficient

\section{Subscripts}

$\mathrm{N} \quad$ Normal condition $\left(1 \mathrm{~atm}, 0{ }^{\circ} \mathrm{C}\right.$ )

LMTD Logarithmic mean temperature difference

\section{References}

[1] National Bureau of Statistics of the People's Republic of China [M]. Beijing: China Statistical Yearbook, 2013.

[2] CAPUTO A C, PELAGAGGE P M. Fuzzy control of heat recovery system from solid bed cooling [J]. Applied Thermal Engineering, 2000, 20(1): 49-67.

[3] CApUto a C, CARDARElli G, PELAGaGge P M. Analysis of heat recovery in gas-solid moving beds using a simulation approach [J]. Applied Thermal Engineering, 1996, 16(1): 89-99.

[4] CAPUTO A C, PELAGAGGE P M. Heat recovery from moving cooling beds: transient modeling by dynamic simulation [J]. Applied Thermal Engineering, 1999, 19(1): 21-35. 
[5] CAPUTO A C, PELAGAGGE P M. Economic design criteria for cooling solid beds [J]. Applied Thermal Engineering, 2001, 21(12): 1219-1230.

[6] PElagagGe P M, CAPUTO A C, CARDARElli G. Comparing heat recovery schemes in solid bed cooling [J]. Applied Thermal Engineering, 1997, 17(11): 1045-1054.

[7] ZHANG Jia-yuan, ZHANG Xiao-hui, ZHOU Jie-min. Optimal orthogonal simulation research of sinter cooling [J]. Iron and Steel, 2011, 46(7): 86-89. (in Chinese)

[8] LEONG J C, JIN K W, SHIAU J S, JENG T M, TAI C H. Effect of sinter layer porosity distribution on flow and temperature fields in a sinter cooler [J]. International Journal of Minerals, Metallurgy and Materials, 2009, 16(3): 265-272.

[9] ZHANG Xiao-hui, ZHANG Jia-yuan, DAI Chuan-de, XIE Dong-jiang. Optimization and simulation of sinter cooling process [J]. CIESC Journal, 2011, 62(11): 3081-3087. (in Chinese)

[10] LIU Yan, YANG Jian, WANG Jin, CHENG Zhi-long, WANG Qiu-wang. Energy and exergy analysis for waste heat cascade utilization in sinter cooling bed [J]. Energy, 2014, 67(1): 370-380.

[11] ZHANG Xiao-hui, CHEN Zhao, ZHANG Jia-yuan, DING Pu-xian, ZHOU Jie-min. Simulation and optimization of waste heat recovery in sinter cooling process [J]. Applied Thermal Engineering, 2013, 54(1): 7-15.

[12] JANG Jiin-yuh, CHIU Yu-wei. 3-D transient conjugated heat transfer and fluid flow analysis for the cooling process of sintered bed $[\mathrm{J}]$. Applied Thermal Engineering, 2009, 29(14/15): 2895-2903.

[13] DONG Hui, ZHAO Yong, CAI Jiu-ju, ZHOU Jie-wang, MA Guang-yu. Leakage of sintering-cooling system [J]. Iron and Steel, 2012, 47(1): 95-99. (in Chinese)

[14] QIAO Wen-cun, YU Zhang-fa, PENG Yan, CHENG Bo, GUO Cun-hong, LU Jian-qiang, WU Jin-ping. Sinter furnace cooling device: China, CN201310127744.5 [P]. 2013-04-15. (in Chinese)

[15] CHENG Bo, PENG Yan, WANG Ji-sheng, GUO Cun-hong, LI Jian-quang, ZHANG Kan-cang, BAO Dong-nan. A furnace heat exchange device for cooling sinter: China, CN201310127825.5 [P]. 2013-04-15. (in Chinese)

[16] ERGUN S. Fluid flow through packed columns [J]. Chemical Engineering Progress, 1952, 48(2): 89-94.

[17] ZHANG Hui-ning. Design manual for sintering process [M]. Beijing: Metallurgical Industry Press, 2008. (in Chinese)

(Edited by YANG Hua) 